\title{
SIMULASI KARAKTERISTIK KEBISINGAN PADA MESIN DLE GAS ENGINE-30 SEBAGAI PENGGERAK PESAWAT TANPA AWAK PROTOTIPE NVC USU
}

\author{
Nazwir F. Damanik ${ }^{1}$, Ikhwansyah Isranuri ${ }^{2}$, M. Sabri ${ }^{3}$, Marragi M. ${ }^{4}$, Farida Ariani ${ }^{5}$ \\ 1,2,3,4,5 Departemen Teknik Mesin, Fakultas Teknik, Universitas Sumatera Utara \\ E-mail : nazwirfahmi@yahoo.co.id
}

\begin{abstract}
ABSTRAK
Pesawat tanpa awak (Unmanned Aerial Vehicle) merupakan sebuah mesin terbang yang dapat dikendalikan dari jarak jauh untuk melakukan misi tertentu. Namun seperti halnya mesin lainnya, permasalahan kebisingan merupakan hal yang tidak terelakkan. Salah satu penyumbang kebisingan pada pesawat adalah mesin. Untuk mengatasi kebisingan tersebut maka perlu dikaji dan di teliti lebih lanjut tentang faktor kebisingan melalui ilmu suara atau akustik dengan menggunakan software simulasi ANSYS yang lebih dikembangkan kepada ilmu Kendali Kebisingan (Noise Control). Dalam hal ini simulasi digunakan karena memiliki kelebihan yaitu dapat melakukan analisa terhadap sistem yang lebih kompleks, kondisi yang dapat disesuaikan dan dapat membandingkan beberapa rancangan alternatif untuk mendapatkan rancangan yang terbaik. Penelitian ini bertujuan untuk melakukan simulasi kebisingan pada mesin pesawat tanpa awak berjenis DLE GAS ENGINE-30. Dari simulasi noise yang dilakukan terhadap mesin DLE Gas Engine-30 maka dapat disimpulkan semakin tinggi putaran mesin semakin sempit range frekuensi suaranya. Dari noise contour yang dihasilkan dari hasil simulasi dapat dilihat bahwa penyebaran suara dari mesin DLE Gas Engine-30 cenderung merata ke setiap arah.
\end{abstract}

Kata kunci : Pesawat tanpa awak, kebisingan, DLE Gas Engine-30, simulasi kebisingan, frekuensi

\section{PENDAHULUAN}

Pesawat tanpa awak (Unmanned Aerial Vehicle) merupakan sebuah mesin terbang yang dapat dikendalikan dari jarak jauh untuk melakukan misi tertentu[1].

Seperti halnya mesin lainnya, permasalahan kebisingan merupakan hal yang tidak terelakkan. Salah satu penyumbang kebisingan pada pesawat adalah mesin. Untuk mengatasi kebisingan tersebut maka perlu dikaji dan di teliti lebih lanjut tentang faktor kebisingan melalui ilmu suara atau akustik dengan menggunakan software simulasi ANSYS yang lebih dikembangkan kepada ilmu Kendali Kebisingan (Noise Control).

Dalam hal ini simulasi digunakan karena memiliki kelebihan yaitu dapat melakukan analisa terhadap sistem yang lebih kompleks, kondisi yang dapat disesuaikan dan dapat membandingkan beberapa rancangan alternatif untuk mendapatkan rancangan yang terbaik.

\section{TINJAUAN PUSTAKA}

\section{Sound Pressure}

Parameter yang dijadikan sebagai bagian dari gelombang suara adalah Sound pressure dan sound power.

Sound presure merupakan fluktuasi dari tekanan udara. Ketika suatu sumber bunyi menghasilkan bunyi, maka bunyi tersebut akan merambat melalui medium udara yang ada disekitarnya.ketika terjadi perambatan,maka terjadi perubahan tekanan atmosfir beberapa saat. 
Sesuatu yang merupakan perubahan tekanan udara sebagai indikasi dari adanya permabatan bunyi inilah yang di sebut dengan sound pressure[2].

\section{Sound Power}

Sound Power merupakan sejumlah daya yang dapat di ukur dihasilkan oleh radiasi sumber bunyi yang menyebar disekitar udara[2]. Secara matemetik, sound power dapat di rumuskan sebagai berikut:

$\mathrm{W}_{\mathrm{s}}=\left(4 \pi \mathrm{r}^{2}\right) I_{\max }($ watt $)$

Untuk mempermudah penentuan nilai kebisingan, maka ada metode yang digunakan dengan menggunakan skala level atau tingkat kebisingan suara dalam satuan decibel (db) yang dibagi menjadi dua kategori yakni sound pressure level dan sound power level.

\section{Sound Power level (SWL)}

Sound power level dapat di rumuskan sebagai berikut[3] :

$$
\mathrm{L}_{\mathrm{w}}=10 \log _{10} \frac{W}{W_{\text {ref }}} \quad(\mathrm{db})
$$

Dimana :

$$
\begin{aligned}
\mathrm{W}= & \text { Sound Power } \\
\mathrm{W}_{\text {reff }}= & \text { Sound power referensi dengan } \\
& \text { standar } 10^{-12} \text { watt }
\end{aligned}
$$

\section{Sound Pressure Level (SPL)}

Hampir setiap pemikiran umum mendefenisikan kata decibel (db) dengan mengaitkan terhadap sound pressure level. Hal seperti ini telah menjadi suatu kesimpulan tersendiri bahwa apabila berbicara tentang skala decibel berarti merupakan suatu hasil perhitungan dari sound pressure level.

Secara matematis sound pressure level dapat di rumuskan sebagai berikut[3] :

$$
\begin{aligned}
\text { SPL } & =L_{p}=10 \log \left[\frac{P^{2}}{P(r e f)^{2}}\right] \\
& =20 \log \frac{p}{p(\text { ref })}
\end{aligned}
$$

Dimana :

$\mathrm{P} \quad=$ tekanan yang terjadi $\left(P_{r m s}\right)$ untuk aliran fluida

$\mathrm{P}(\mathrm{ref})=$ tekanan pada air borne

$$
=2 \times 10^{-5} \mathrm{~N} / \mathrm{m}^{2}=20 \mu \mathrm{Pa}
$$

\section{Noise}

Noise adalah suatu sinyal gangguan yang bersifat akustik (suara), elektris, maupun elektronis yang hadir dalam suatu sistem dalam bentuk gangguan yang bukan merupakan sinyal yang diinginkan[4].

Sumber noise dapat dikelompokkan dalam tiga kategori:
1. Sumber noise intrinsic yang muncul
dari fluktuasi acak
di dalam suatu sistemfisik seperti thermal dan shot noise.

2. Sumber noise buatan manusia seperti motor, switch, elektronika digital. 
3. Noise karena gangguan alamiah seperti petir dan bintik matahari.

Tabel 2.1 Contoh SPL Berdasarkan Sumbernya[5]

\begin{tabular}{lll}
\hline No & $\begin{array}{l}\text { Sound Sources(Noise) } \\
\text { Examples with Distance }\end{array}$ & SPL(dB) \\
\hline 1. & Jet aircraft, 50 m away & 140 \\
2 & Threshold of pain & 130 \\
3 & Threshold of discomfort & 120 \\
4 & Chainsaw, 1 m distance & 110 \\
5 & Disco, 1 m from speaker & 100 \\
6 & Diesel truck, 10 m away & 90 \\
7 & Kerbside of busy road, 5m & 80 \\
8 & Vacuum cleaner, distance & 70 \\
9 & 1 m & 60 \\
10 & Conversational speech, 1 & 50 \\
11 & m & 40 \\
12 & Average home & 30 \\
13 & Quite library & 20 \\
14 & Quite bedroom at night & 10 \\
15 & Background in TV studio & 0 \\
& Rustiling leaves in the & \\
& distance & \\
\hline
\end{tabular}

\section{Noise Contour}

Sebuah Kontur Kebisingan merupakan distribusi dari sumber kebisingan yang di gambarkan dalam bentuk garis yang bersambung dan tidak dapat bertemu atau memotong garis kontur lainnya dan tidak pula dapat bercabang menjadi garis kontur yang lain. Kontur kebisingan digunakan untuk menentukan distribusi sebaran bunyi sebagai bagian dari pengandalian kebisingan[6].

\section{Mesin DLE Gas Engine-30}

Mesin DLE Gas Engine-30 adalah mesin 2 tak dengan kapasitas 30 cc. Tenaga maksimal yang dapat dikeluarkan adalah 3.7HP pada putaran $8500 \mathrm{rpm}$. Seperti mesin 2 tak pada umumnya, mesin DLE Gas Engine-30 memiliki nilai tingkat kebisingan yang cukup tinggi. Nilai kebisingan maksimum dari mesin ini adalah 106,6 dB pada putaran $7000 \mathrm{rpm}$.

\section{METODOLOGI PENELITIAN}

\section{Tempat dan Waktu}

Penelitian ini direncanakan berlangsung selama \pm 3 bulan. Penelitian ini dilaksanakan di Laboratorium Noise and Vibration Control program Magister dan Doktoral Teknik Mesin Fakultas Teknik Universitas Sumatera Utara.

\section{Bahan dan Alat Penelitian}

Pada penelitian ini mesin yang digunakan adalah mesin gasoline bertipe DLE-30. Berikut adalah spesifikasi data yang dimiliki mesin ini: 

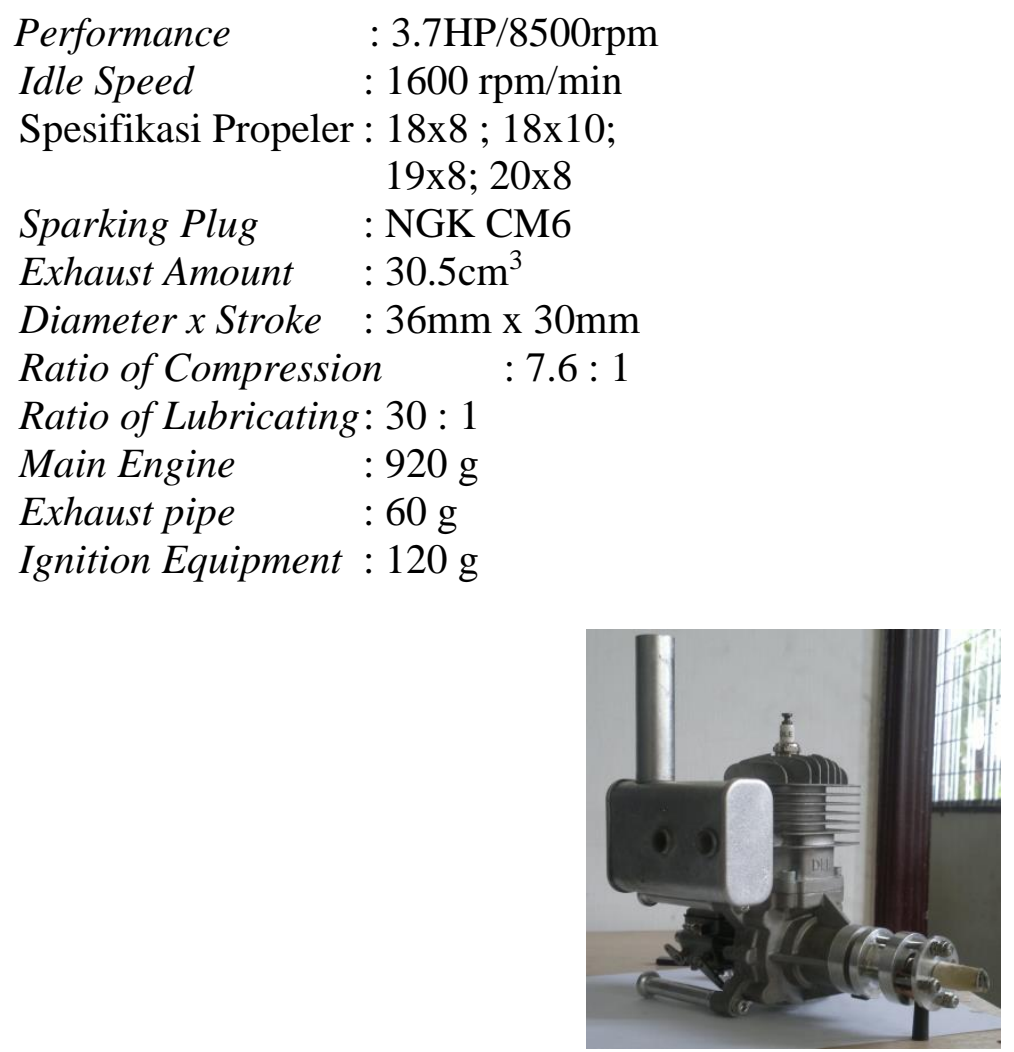

Gambar 3.1 Mesin DLE Gas Engine

\section{Alat Penelitian}

Pengujian yang dilakukan merupakan jenis pengujian komputasional dengan menggunakan seperangkat komputer dengan spesifikasi:

- Processor : Core i3 (4core)

- Ram : $6 \mathrm{~Gb}$

- Software : Ansys 15.0

- VGA : Intel HD $1 \mathrm{~Gb}$

\section{Variabel Yang Diamati}

Ditentukan dua buah variabel penelitian, yakni variabel terikat dan variabel bebas.

\section{Variabel Terikat}

Untuk menyederhanakan permasalahan dalam kajian kebisingan pada mesin pesawat UAV, maka dalam penelitian ini di tetapkan variable terikat yakni:

1. Sifat properties dari udara

\section{Variabel Bebas}

Variabel bebas pada penelitian ini merupakan pengaruh yang diakibatkan oleh adanya variabel terikat dan ditetapkan dalam dua hal yakni:

1. Putaran mesin

2. Frekuensi bunyi mesin

\section{Analisa Data}




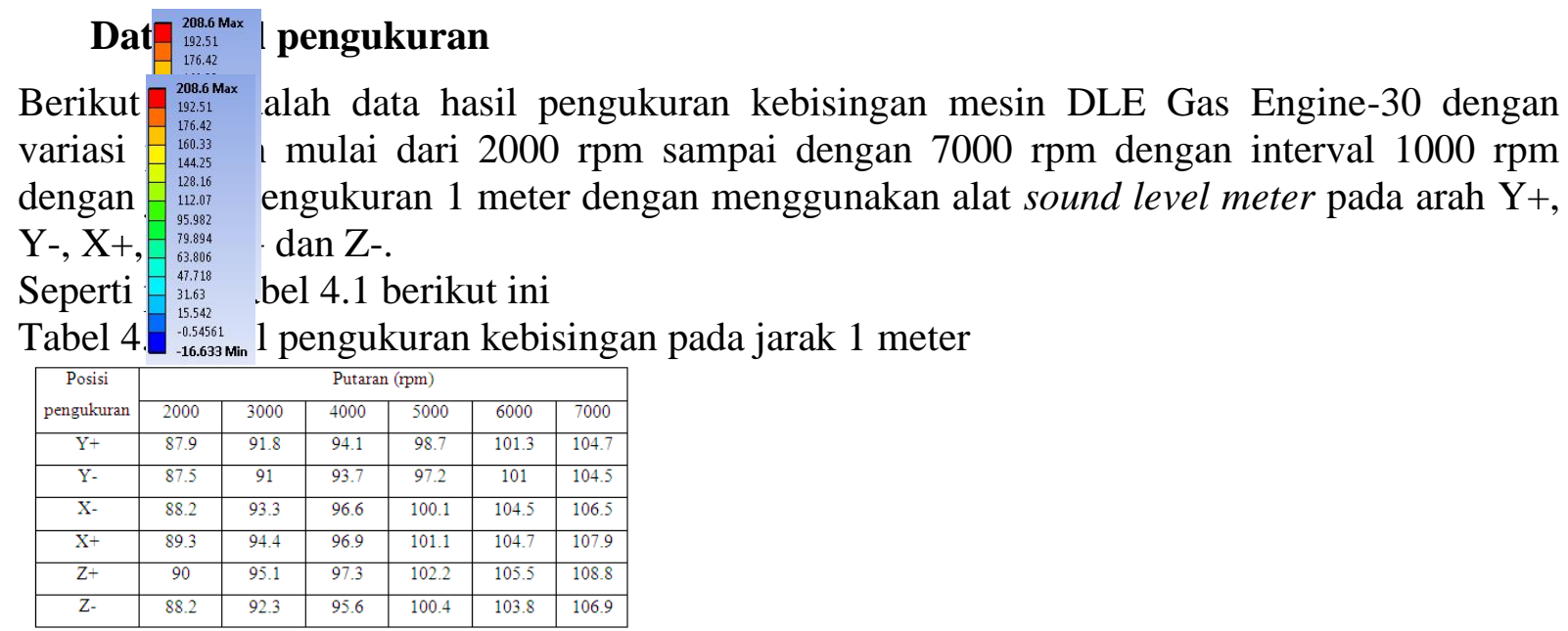

\section{Hasil Simulasi}

Hasil yang diperoleh adalah berupa kontur noise yang ditunjukkan oleh warna-warna yang menunjukkan besarnya SPL (Sound Pressure Level) yang tereksitasi ke udara di sekitar mesin. Putaran mesin divariasikan mulai dari $2000 \mathrm{rpm}$ hingga $7000 \mathrm{rpm}$ dengan interval $1000 \mathrm{rpm}$. Setiap putaran mesin memiliki range frekuensi yang berbeda pada suara yang dihasilkan. Simulasi dilakukan dengan memasukkan rentang frekuensi tertentu dan mencocokkan hasil simulasi dengan hasil pengukuran kebisingan yang diukur dengan sound level meter.

Dalam melakukan proses pencocokan hasil, yang diambil sebagai acuan adalah hasil pengukuran pada titik $\mathrm{Y}+$. Titik $\mathrm{Y}+$ dipilih karena hasil pengukuran pada titik ini dianggap paling akurat.

1. Putaran $2000 \mathrm{rpm}$
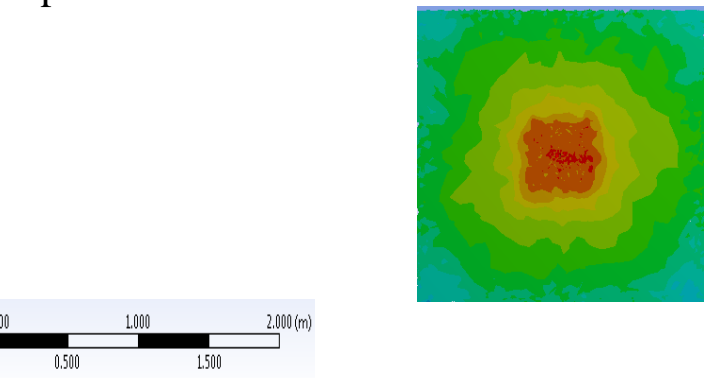

(a)

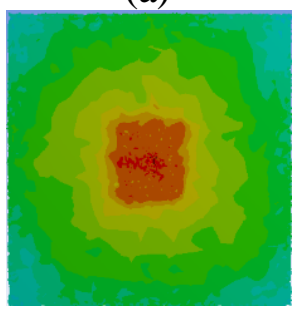

(b) 

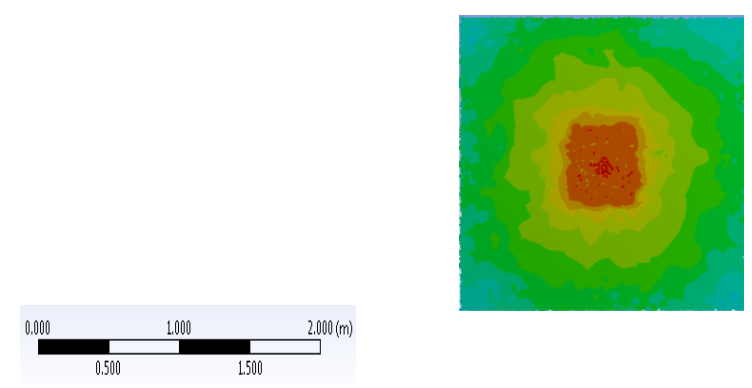

(c)

Gambar 4.1 Noise Contour pada mesin (jarak 1m, 2000 rpm) (a) Noise Contour pada bidang XY (b) Noise Contour pada bidang XZ (c) Noise Contour pada bidang YZ

Dari simulasi yang dilakukan, diketahui bahwa range frekuensi noise pada putaran 2000 rpm adalah $3000 \mathrm{~Hz}-9500 \mathrm{~Hz}$.

2. Putaran $3000 \mathrm{rpm}$
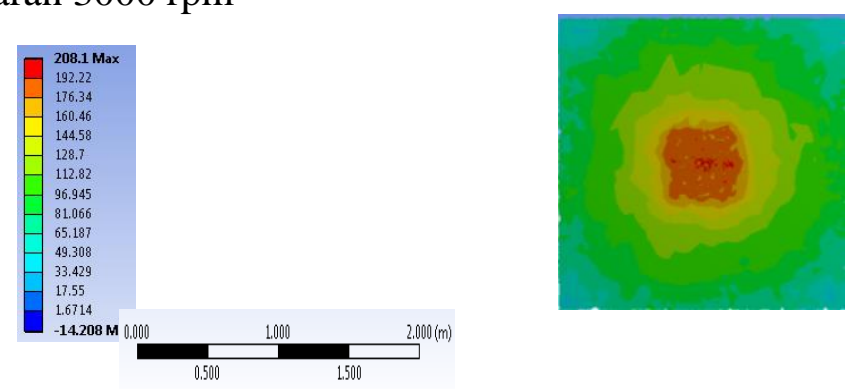

(a)
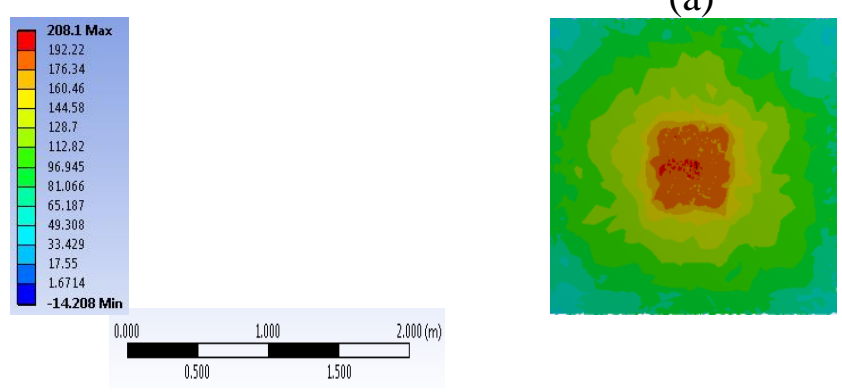

(b)
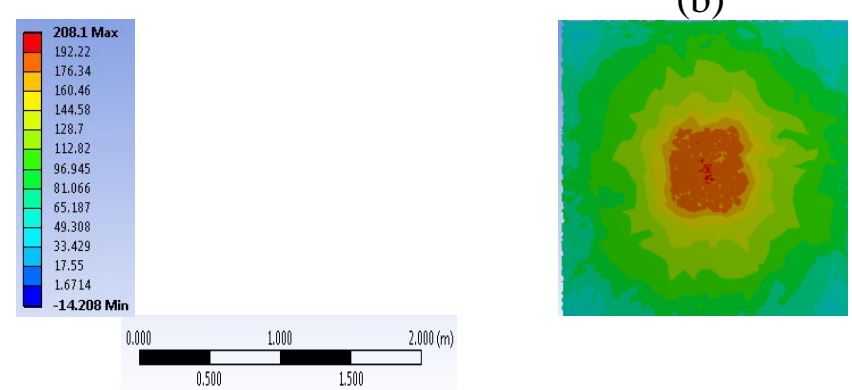

(c)

Gambar 4.2 Noise Contour pada mesin (jarak 1m, 3000 rpm) (a) Noise Contour pada bidang XY (b) Noise Contour pada bidang XZ (c) Noise Contour pada bidang YZ 
Dari simulasi yang dilakukan, diketahui bahwa range frekuensi noise pada putaran 3000 rpm adalah $3000 \mathrm{~Hz}-8850 \mathrm{~Hz}$.

3. Putaran $4000 \mathrm{rpm}$
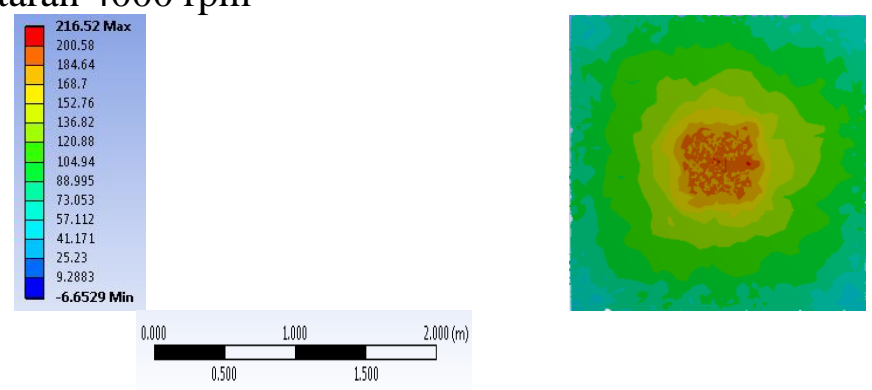

(a)
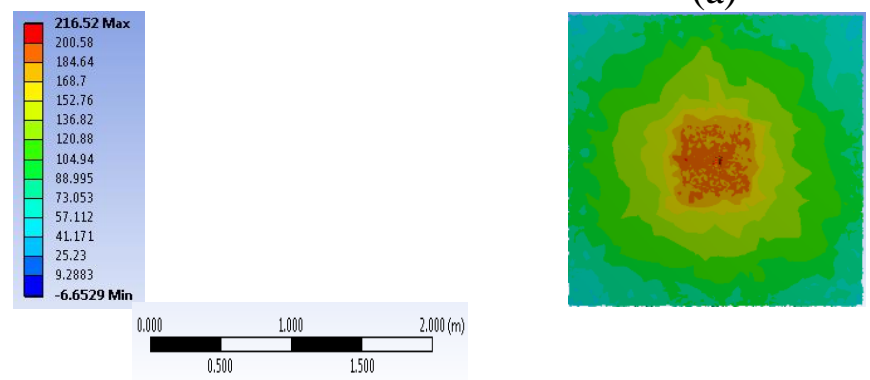

(b)
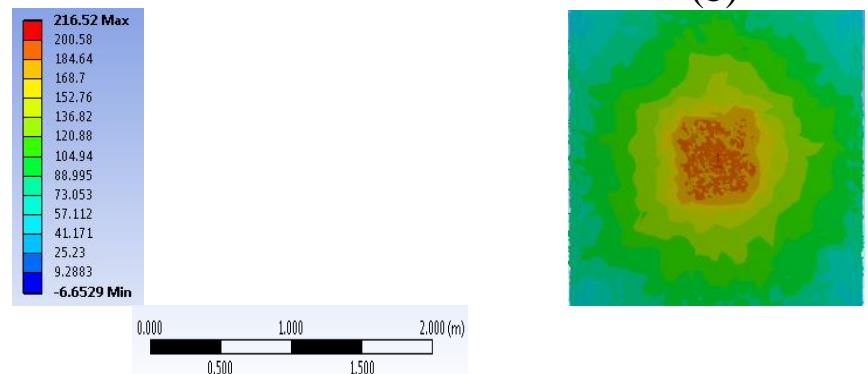

(c)

Gambar 4.3 Noise Contour pada mesin (jarak 1m, 4000 rpm) (a) Noise Contour pada bidang XY (b) Noise Contour pada bidang XZ (c) Noise Contour pada bidang YZ

Dari simulasi yang dilakukan, diketahui bahwa range frekuensi noise pada putaran 4000 rpm adalah $3000 \mathrm{~Hz}-8500 \mathrm{~Hz}$.

\section{Putaran $5000 \mathrm{rpm}$}
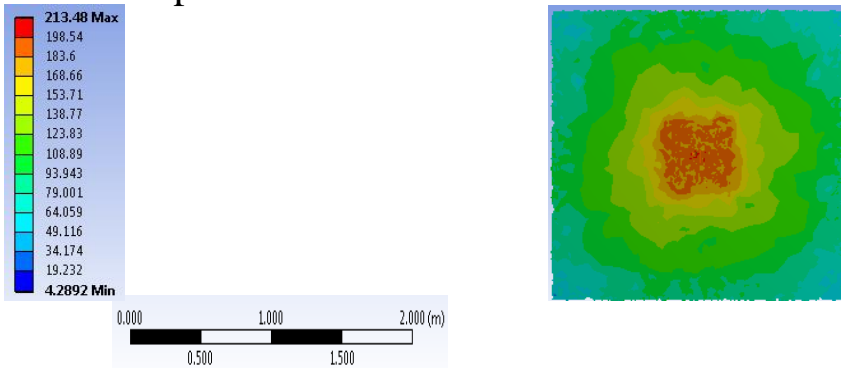

(a) 

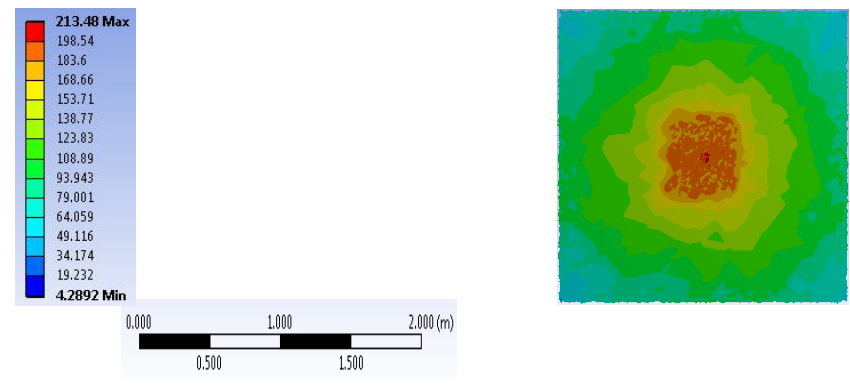

(b)
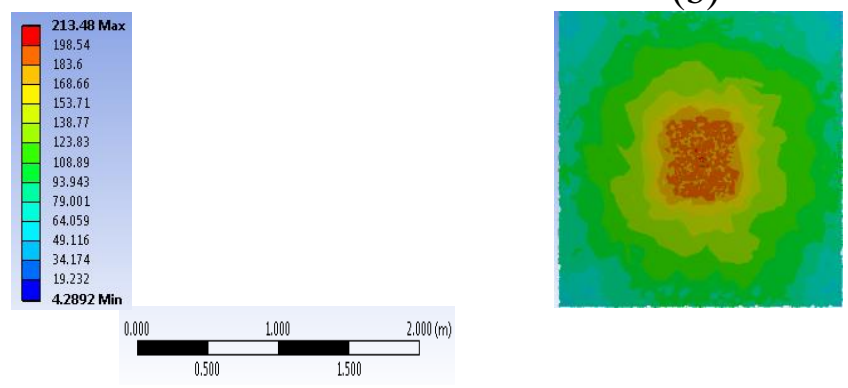

(c)

Gambar 4.4 Noise Contour pada mesin (jarak 1m, 5000 rpm) (a) Noise Contour pada bidang XY (b) Noise Contour pada bidang XZ (c) Noise Contour pada bidang YZ

Dari simulasi yang dilakukan, diketahui bahwa range frekuensi noise pada putaran 5000 rpm adalah $3000 \mathrm{~Hz}-8000 \mathrm{~Hz}$.

5. Putaran $6000 \mathrm{rpm}$
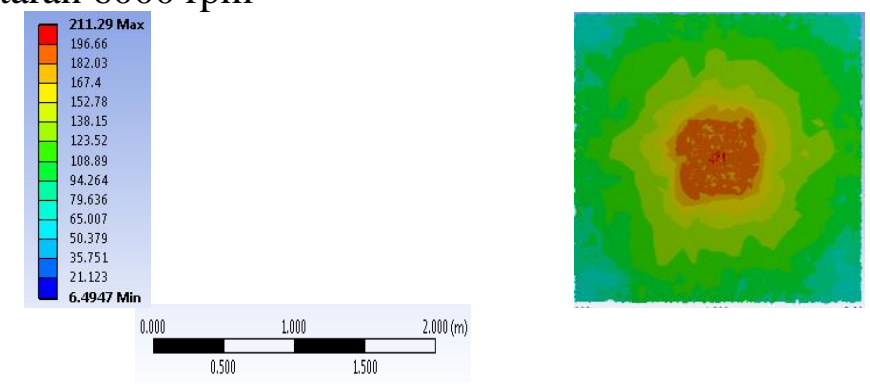

(a)

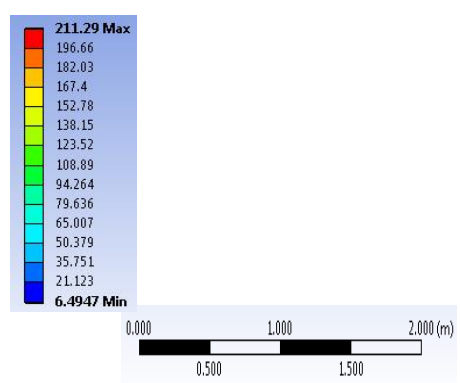

(b) 

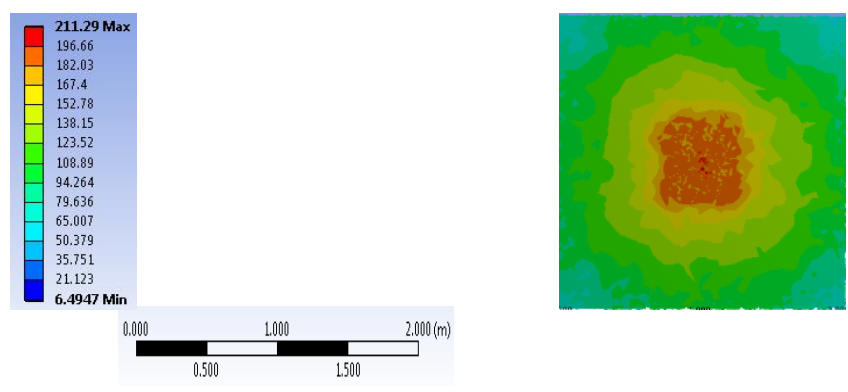

(c)

Gambar 4.5 Noise Contour pada mesin (jarak 1m, 6000 rpm) (a) Noise Contour pada bidang XY (b) Noise Contour pada bidang XZ (c) Noise Contour pada bidang YZ

Dari simulasi yang dilakukan, diketahui bahwa range frekuensi noise pada putaran 6000 rpm adalah $3000 \mathrm{~Hz}-7000 \mathrm{~Hz}$.

6. Putaran 7000 rpm
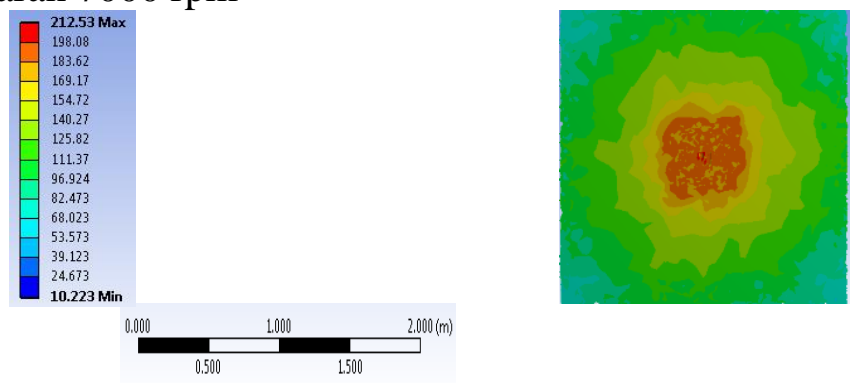

(a)
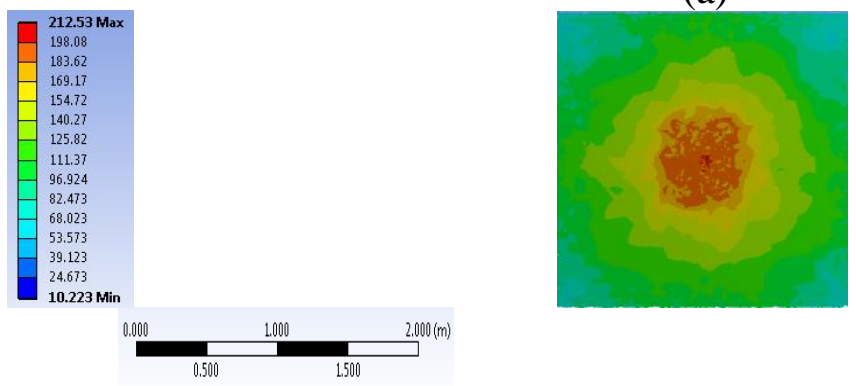

(b)
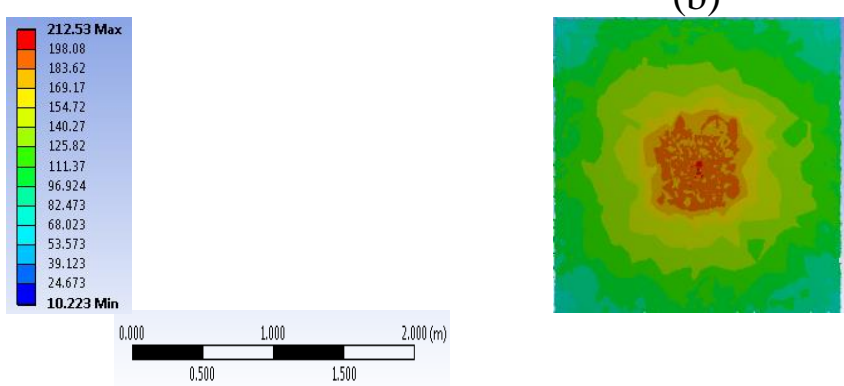

(c)

Gambar 4.6 Noise Contour pada mesin (jarak 1m, 7000 rpm) (a) Noise Contour pada bidang XY (b) Noise Contour pada bidang XZ (c) Noise Contour pada bidang YZ 
Dari simulasi yang dilakukan, diketahui bahwa range frekuensi noise pada putaran 7000 rpm adalah $3000 \mathrm{~Hz}-6500 \mathrm{~Hz}$.

\section{Rekapitulasi Karakteristik Noise}

Berikut ini adalah grafik hasil simulasi kebisingan pada mesin DLE Gas Engine-30 dengan variasi putaran mulai dari $2000 \mathrm{rpm}$ sampai dengan $7000 \mathrm{rpm}$ dengan interval $1000 \mathrm{rpm}$ pada jarak 1 meter pada arah $\mathrm{Y}+, \mathrm{Y}-, \mathrm{X}+, \mathrm{X}-, \mathrm{Z}+$ dan $\mathrm{Z}-$.

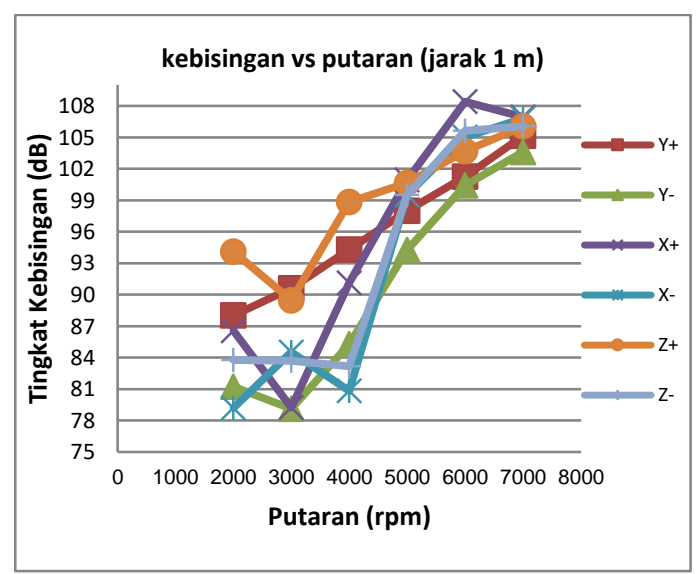

Gambar 4.7 Grafik tingkat kebisingan vs putaran hasil simulasi

Dari grafik terlihat bahwa nilai kebisingan pada setiap titik pengukuran tidak naik seiring dengan naiknya putaran mesin. Pada titik pengukuran Y- nilai kebisingan terendah pada putaran $3000 \mathrm{rpm}$ dengan nilai $79.116 \mathrm{~dB}$ dan nilai kebisingan tertinggi pada putaran 8000 rpm dengan nilai $103.61 \mathrm{~dB}$. Pada titik X+ nilai kebisingan terendah pada putaran 3000 rpm dengan nilai $79.244 \mathrm{~dB}$ dan nilai kebisingan tertinggi pada putaran $7000 \mathrm{rpm}$ dengan nilai $108.4 \mathrm{~dB}$. Pada titik X- nilai kebisingan terendah pada putaran $2000 \mathrm{rpm}$ dengan nilai $79.207 \mathrm{~dB}$ dan nilai kebisingan tertinggi pada putaran $7000 \mathrm{rpm}$ dengan nilai $106.8 \mathrm{~dB}$. Pada titik Z+ nilai kebisingan terendah pada putaran $3000 \mathrm{rpm}$ dengan nilai $89.471 \mathrm{~dB}$ dan nilai kebisingan tertinggi pada putaran $7000 \mathrm{rpm}$ dengan nilai $106.06 \mathrm{~dB}$. Pada titik Z- nilai kebisingan terendah pada putaran $4000 \mathrm{rpm}$ dengan nilai $83.173 \mathrm{~dB}$ dan nilai kebisingan tertinggi pada putaran $7000 \mathrm{rpm}$ dengan nilai $106.05 \mathrm{~dB}$.

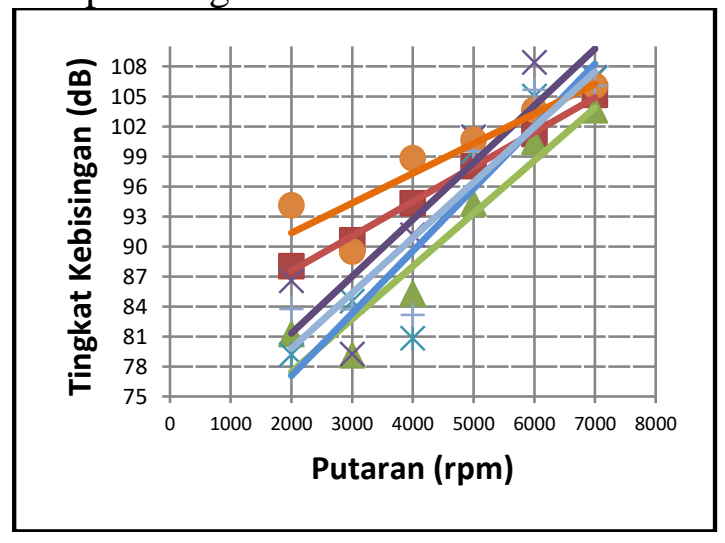

Gambar 4.8 Grafik regresi linear tingkat kebisingan vs putaran hasil simulasi 
Gambar 4.8 menunjukkan grafik regresi linear kebisingan vs putaran hasil simulasi untuk menunjukkan peningkatan nilai tingkat kebisingan dengan naiknya putaran mesin.

\section{KESIMPULAN DAN SARAN}

\section{Kesimpulan}

Berdasarkan hasil simulasi yang telah dilakukan dan dilaporkan pada bab-bab sebelumnya, maka kesimpulan dari hasil penelitian ini yaitu:

1. Dari simulasi noise yang dilakukan terhadap mesin DLE Gas Engine-30 maka dapat disimpulkan semakin tinggi putaran mesin semakin sempit range frekuensi suaranya.

2. Dari noise contour yang dihasilkan dari hasil simulasi dapat dilihat bahwa penyebaran suara dari mesin DLE Gas Engine-30 cenderung merata ke setiap arah.

\section{Saran}

1. Untuk penelitian selanjutnya, agar melakukan pengukuran terhadap frekuensi dari noise agar dapat dilakukan perbandingan dengan pengukuran kebisingan secara eksperimental.

2. Melakukan simulasi dengan menambahkan body pesawat sebagai material serap bising.

3. Dari hasil simulasi dapat juga dilakukan redaman kebisingan dengan merubah paduan material dari body pesawat.

\section{DAFTAR PUSTAKA}

[1]Ardhianto , Kurniawan. 2011. Desain dan Analisis Propeller pada Unmanned Aerial Vehicle $(U A V)$. AAU Journal of Defense Science and Technology Volume 2, Number 1, 1 July $2011,125-133$.

\section{[2]Harris, Cyril M.1957. Handbook of Noise Control}

[3] Bies, David A and C.H. Hansen. 1988. Engineering Noise Control: Theory and Practice. New York : Unwin Hyman

[4]Barron,Randall F. 2001. Industrial Noise Control and Acoustics. New-York :Marcel Dekker, Inc

[5]http://www.TableOfSoundPressureLevels.htm

[6]Graham, J.B. (1991) in Harris, C.M. Handbook of acoustical measurements and noise control. 